\title{
DNA TYPING OF HLA IN THE PATIENTS WITH MOYAMOYA DISEASE
}

\author{
Takuya K. INOUE, ${ }^{1, *}$ Kiyonobu IKEZAKI, ${ }^{1}$ Takehiko SASAZUKI, ${ }^{2}$ \\ Takashi ONO, ${ }^{2}$ Nobuhiro KamiKawaJI, ${ }^{2}$ Toshio Matsushima, ${ }^{1}$ \\ and Masashi FuKUI ${ }^{1}$ \\ ${ }^{1}$ Department of Neurosurgery, Neurological Institute, Faculty of Medicine, \\ and ${ }^{2}$ Department of Genetics, Medical Institute of Bioregulation, \\ Kyushu University, Fukuoka 812-82, Japan
}

\begin{abstract}
Summary Moyamoya disease is a clinical entity demonstrating a chronic occlusion of the cerebrovascular system. Although some possible etiological factors have been postulated, the etiology of this disease is still unknown. So far, some investigations have suggested the association between moyamoya disease and HLA in the serological typing. However, DNA typing of HLA have not been performed yet. Thus, we performed DNA-typing of HLA in the unrelated Japanese patients with definite moyamoya disease, using the polymerase chain reaction-sequence specific oligonucleotide probe (PCR-SSOP) technique. In the total patients, $D Q B 1^{*} 0502$ had a positive association with the disease. On the other hand, $D R B 1^{*} 0405$ and $D Q B 1^{*} 0401$ showed a negative association. In comparing the early-onset and late-onset groups, two groups did not share the same disease associated alleles at all. Thus, the etiology of moyamoya disease seem to have a genetic background. Furthermore, different genetic factors might also be involved in the difference between the early-onset and late-onset groups.

Key Words moyamoya disease, genetic, HLA typing
\end{abstract}

\section{INTRODUCTION}

Moyamoya disease is a clinical entity with chronic occlusion of cerebrovascular system characterized by progressive steno-occlusive changes at the terminal portion of the bilateral internal carotid arteries (Kudo, 1968; Nishimoto and Takeuchi, 1968). An unusual vascular network at the base of the brain represents secondary collateral formation due to ischemic changes caused by a progressive occlusion of the circle of Willis (Suzuki and Takaku, 1969).

The estimated number of patients in Japan in 1994 was 3,900 (95\% confidence

Received October 6, 1997; Accepted October 22, 1997.

* To whom correspondence should be addressed. 
interval; 3,500-4,400). The prevalence and incidence rates are calculated to be 3,16 and 0.35 per 100,000 population, respectively (Wakai et al., 1996). The onset age distribution of this disease is bimodal. The incidence of the disease is highest during the first decade of life, while the second peak occurs in the third decade (Fukui and Kawano, 1996).

Several hypotheses have been put forward to explain the etiology of moyamoya disease, such as an upper respiratory tract infection (Suzuki and Kodama, 1983), a disorder of the autoimmune system (Kitahara et al., 1982), thrombogenesis on the intima (Ikeda and Hosoda, 1993; Ikeda et al., 1993), an abnormality of vascular smooth muscle cells (Masuda et al., 1993; Aoyagi et al., 1993; Suzuki et al., 1994).

Furthermore, there is some evidence for a genetic background: 1) There are remarkable ethnic differences in the frequency of moyamoya disease in the world. Asians, such as Japanese and Koreans, have a higher rate of disease. A total of 1,063 cases of moyamoya disease have been reported, occurred worldwide excluding Japan and 625 of these cases were observed in Asians (Goto and Yonekawa, 1992; Ikezaki et al., 1997); 2) The familial occurrence rate is about $10 \%$ in patients with moyamoya disease. Ten pairs of monozygotic twins have also been registered as having the disease in Japan. The incidence rate of parents and siblings in patients with moyamoya disease is from 30 to 40 -fold higher than that in the general population (Kanai and Fukuyama, 1992); 3) Angiographic findings similar to moyamoya disease have been seen in well-known genetic chromosomal disorders, such as neurofibromatosis (Woody et al., 1992), Fanconi anemia (Pavlakis et al., 1995) and Down syndrome (Gadoth, 1993). The responsible gene of neurofibromatosis is located on chromosome $17 \mathrm{q}$ or $22 \mathrm{q}$. A complementation group of Fanconi anemia is related to chromosome $9 \mathrm{q}$, while Down syndrome is known to demonstrate 21-trisomy; and 4) Previous serological typing of HLA in moyamoya disease revealed associations between the disease and $A w 24, B w 46$ and $B w 54$ antigens in 18 patients (Kitahara et al., 1982), or $B 51, B 67, D R I$ and $C w 1$ antigens in 32 patients (Aoyagi et al., 1995)

The purpose of this study is, thus, to elucidate the genetic factors that may control the susceptibility to moyamoya disease by performing DNA typing of HLA genes in a large number of unrelated Japanese patients with this disease.

\section{MATERIALS AND METHODS}

Study subjects. The study subjects were all Japanese living in Japan. All patients were diagnosed as having definite moyamoya disease according to the guidelines for the diagnosis of moyamoya disease established in 1988 by the Research Committee on the Spontaneous Occlusion of the Circle of Willis (moyamoya disease) of the Ministry of Health and Welfare, Japan (Kitamura, 1988). Seventy-one unrelated patients with moyamoya disease thus underwent 
Table 1. Number of patients analyzed.

\begin{tabular}{lcccc} 
& \multicolumn{2}{c}{$H L A-A$} & \multicolumn{2}{c}{ Class II genes } \\
\hline Age at onset & $\leq 10$ & $>10$ & $\leq 10$ & $>10$ \\
$\begin{array}{l}\text { Number of patient }\left(\mathrm{F} / \mathrm{M}^{*}\right) \\
\text { Total }\end{array}$ & $48(31 / 17)$ & $20(16 / 4)$ & $49(32 / 17)$ & $22(18 / 4)$ \\
\hline F & \multicolumn{2}{c}{68} & \multicolumn{2}{c}{71} \\
\hline
\end{tabular}

${ }^{*} \mathrm{~F} / \mathrm{M}=$ female $/$ male.

DNA typing for class II genes. Sixty-eight of these patients underwent class I typing. In addition, 525 unrelated healthy Japanese were used as control subjects.

Table 1 shows the number of patients and the sex ratio. Because the onset age distribution of moyamoya disease is bimodal, the patients were divided into two groups according to the onset age, including the early-onset group, with patients 10 years old and under, and the late-onset group, with patients older than 10 years old. Regarding the genotype of class $I$ genes, 48 patients were analyzed in the early-onset group and 20 patients in the late-onset group, while for the class II genes, 49 patients were analyzed in early-onset group and 22 patients in late-onset group.

This study was approved by the Research Committee and each institutional review board and informed consent was obtained from each patient.

$H L A$ typing. Regarding the class $I$ genes of HLA, the $H L A-A$ gene was examined, while for the class II genes, HLA-DRBI,DQA1,DQB1,DPAI and $D P B I$ genes were examined. The allele designations are from the WHO HLA Nomenclature Committee (Bodmer et al., 1995). The method of DNA typing of HLA has been described previously (Kimura and Sasazuki, 1992; Kimura et al., 1992; Date et al., 1996).

Genomic DNA was extracted from peripheral granulocytes by the standard sodium dodecyl sulfate (SDS)-proteinase $\mathrm{K}$ digestion/phenol-chloroform extraction method. The polymerase chain reaction (PCR) mixture was composed of genomic DNA $(0.2 \mu \mathrm{g}), 1$ unit of Taq DNA polymerase (Takara Taq, Takara Co., Kyoto, Japan), 15 pmol of a $5^{\prime}$-sided primer and a $3^{\prime}$-sided primer, $5 \mu 1$ of $2 \mathrm{~mm}$ deoxyribonucleoside triphosphates (d-NTP), $5 \mu \mathrm{l}$ of $10 \times \mathrm{PCR}$ buffer $(500 \mathrm{~mm}$ $\mathrm{KCl}, 20 \mathrm{mM} \mathrm{MgCl}{ }_{2} 1 \mathrm{mg} / \mathrm{ml}$ Gelatin, $0.2 \% \mathrm{NP}-40$, and $100 \mathrm{mM}$ Tris-HCl, $\mathrm{pH}$ 8.4) in a final volume of $50 \mu \mathrm{l}$. PCR was done in a Thermal Cycler (Perkin Elmer Cetus, Norwalk, CT).

The PCR products were spotted onto nylon filters (Biodyne B; Pall Co., East Hills, NY), immobilized by alkaline denaturation in $0.4 \mathrm{~N} \mathrm{NaOH}$, and neutralized in $10 \times \mathrm{SSPE}$ solution $(1.5 \mathrm{M} \mathrm{NaCl}, 0.1 \mathrm{M}$ sodium phosphate, and $10 \mathrm{~mm}$ disodium ethylene-diamine-tetra-acetate- $2 \mathrm{H}_{2} \mathrm{O}$ (EDTA), $\mathrm{pH}$ 7.4). The filters were prehybridized for $1 \mathrm{hr}$ at $54^{\circ} \mathrm{C}$ in hybridization buffer $(50 \mathrm{mM}$ Tris- $\mathrm{HCl}, 3 \mathrm{M}$ tetramethylammonium chloride, $2 \mathrm{mM}$ EDT A, $5 \times$ Denhardt's solution, $0.1 \%$ SDS, and $100 \mu \mathrm{g} / \mathrm{ml}$ heat-denatured herring sperm DNA, pH 8.0). After hybridization with ${ }^{32} \mathrm{P}$-endlabeled sequence-specific oligonucleotides (SSOPs) at $54^{\circ} \mathrm{C}$ for $1 \mathrm{hr}$, the filters were washed twice to remove any excess SSOPs in $2 \times$ SSPE and $0.1 \%$ SDS 
at room temperature for $10 \mathrm{~min}$. The filters were, then, washed once for $10 \mathrm{~min}$ at room temperature in TMAC solution $(50 \mathrm{mM}$ Tris- $\mathrm{HCl}, 3 \mathrm{M}$ tetra-methylammonium chloride, $2 \mathrm{~mm}$ EDT A, 0.1\% SDS, pH 8.0). Another stringent wash was done twice for $10 \mathrm{~min}$ at $58^{\circ} \mathrm{C}$ in TMAC solution. The filters were then exposed to $\mathrm{X}$-ray film for $1 \mathrm{hr}$ at room temperature to detect hybridization signals.

Statistics. The strength of the statistical association between the disease and HLA was expressed by the relative risk as given by Woolf's formula (Woolf, 1955; Miettinen, 1976) with Haldane's modification (Haldane, 1956). The statistical significance was examined by the chi-square test with Yates' correction. When the $p$ value was less than 0.05 , the association with each individual allele was considered to be significant.

\section{RESULTS}

The frequency of the HLA alleles in the patients with moyamoya disease was compared with the distribution of alleles in the control population.

In the total patients, the frequencies of $D R B 1^{*} 0502$ (10\% vs 3\%, phenotype frequency in the patients versus that in the controls; chi-sq: chi-square value $=$ 5.485 , R.R.: relative risk $=3.27, \mathrm{p}<0.025$ ) showed a significantly positive association with the disease. On the other hand, the frequencies of $D R B I^{*} 0405(11 \%$ vs $27 \%$; chi-sq $=7.142$, R.R. $=0.35, \mathrm{p}<0.01)$ and $D Q B 1^{*} 0401$ (13\% vs 26\%; chi-sq $=$ 5.663, R.R. $=0.4, \mathrm{p}<0.025$ ) were significantly lower in the patients than in the control (Table 2).

In the early-onset group, the frequencies of $A^{*} 2602$ (13\% vs 4\%; chi-sq $=4.868$, R.R. $=3.42, \mathrm{p}<0.05), D R B I^{*} 1501$ ( $24 \%$ vs $12 \%$; chi-sq $=4.663, \mathrm{R} . \mathrm{R} .=2.3, \mathrm{p}<0.05$ ) and $D Q B 1^{*} 0602(24 \%$ vs $12 \%$; chi-sq $=5.337, \mathrm{R} . \mathrm{R} .=2.42, \mathrm{p}<0.025)$ showed a significantly positive association with the disease. On the other hand, the frequencies of $D R B I^{*} 0405$ ( $12 \%$ is $27 \%$; chi-sq $\left.=4.185, \mathrm{R} . \mathrm{R} .=0.38, \mathrm{p}<0.05\right)$ were significantly lower in the moyamoya patients (Table 2 ).

In the late-onset group, the frequencies of $D Q A I^{*} 0301$ (36\% vs 15\%; chi-sq= 5.503, R.R. $=3.18, \mathrm{p}<0.025$ ) and $D Q B 1^{*} 0502$ (14\% vs 3\%; chi-sq = 3.865, R.R.= $4.72, \mathrm{p}<0.05)$ showed a positive association with the disease. On the other hand, the frequencies of $D Q A 1^{*} 0302$ ( $32 \%$ vs $57 \%$; chi-sq $=4.363$, R.R. $=0.36, \mathrm{p}<0.05$ ) were significantly lower in the moyamoya patients (Table 2). There were no common alleles, which showed significant association in either groups. Furthermore, there were no significant differences in the affected alleles between females and males (data not shown).

The frequencies of the $D R-D Q$ haplotypes in moyamoya disease are shown in Table 3. In the total patients, the $D R B 1^{*} 0802-D Q A 1^{*} 0401-D Q B 1^{*} 0402$ haplotype $(4.2 \%$ vs $2.5 \%$; chi-sq $=4.23$, R.R. $=1.76, \mathrm{p}<0.05)$ showed a positive association, whereas the $D R B 1^{*} 0405-D Q A 1^{*} 0302-D Q B 1^{*} 0401$ haplotype (11\% vs 27\%; chi-sq $=6.99$, R.R. $=0.353, \mathrm{p}<0.01$ ) showed a negative association with the disease. 
DNA TYPING OF HLA IN MOYAMOYA DISEASE
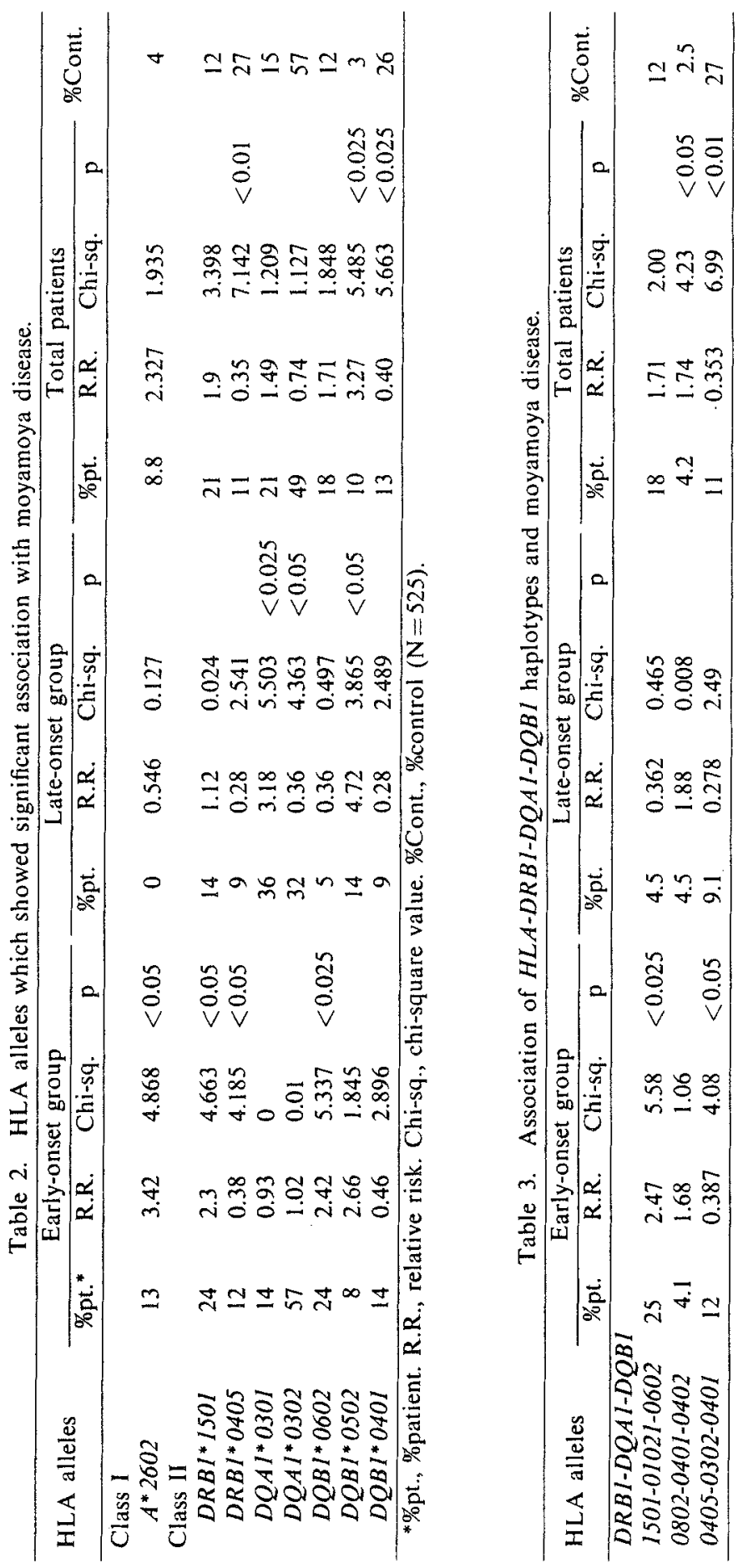

Vol. 42, No. 4, 1997 
In the early-onset group, the $D R B 1^{*} 1501-D Q A 1^{*} 01021-D Q B 1^{*} 0602$ haplotype $(25 \%$ vs $12 \%$; chi-sq $=5.58, \mathrm{R} . \mathrm{R} .=2.47, \mathrm{p}<0.025)$ showed a positive association with the disease, whereas the frequencies of the $D R B 1^{*} 0405-D Q A 1^{*} 0302-$ $D Q B 1^{*} 0401$ haplotype $(12 \%$ vs $27 \%$; chi-sq $=4.08, \mathrm{R} . \mathrm{R} .=0.387, \mathrm{p}<0.05)$ showed a negative association with the disease.

In the late onset group, none of the haplotype disease association showed statistical significance.

\section{DISCUSSION}

The present study demonstrated that several HLA alleles had a significant association with moyamoya disease $(\mathrm{p}<0.05$ with Yates' correction). Furthermore, a significant difference was seen in the affected alleles between the early-onset and the late-onset groups.

The HLA plays an important role in controlling the immune system and is known to be associated with various diseases such as auto-immune diseases (Todd et al., 1988; Sasazuki et al., 1983), infectious diseases (Hirayama et al., 1987; Nishimura and Sasazuki, 1987) and virus-associated tumors (Burt et al., 1994).

The frequency of $D R B 1^{*} 0405$ is lower than that in the controls, both in patients with Takayasu arteritis (10.9\%) (Dong et al., 1992) and moyamoya disease (11\%) as demonstrated in the current study. Furthermore, the frequency of the $D R B 1^{*}$ 1501-DQA1*01021-DQB1*0602 haplotype is higher in patients with systemic lupus erythematodes (32.1\%) (Dong et al., 1993) and moyamoya disease (25\%) than in the controls.

There are two possibilities which may explain the association of HLA alleles with the disease. One is that these alleles directly control the susceptibility to moyamoya disease and the other is that other responsible genes have linkage disequilibrium with disease-associated HLA alleles (Achord et al, 1982; Hugot et al., 1994).

If these alleles directly control the susceptibility to moyamoya disease, it may be that moyamoya disease in some way is related to autoimmune vasculitis. However, histopathological investigations have not revealed any evidence of active inflammation in the terminal portion of the internal carotid arteries (Hosoda, 1984; Yamashita et al., 1991). Since most histopathological examinations of this disease have only been conducted in adult bleeding cases, it remains unclear as to what kind of pathological changes exist in the most active state in younger aged patients. There has only been one case in which inflammatory change caused angiographic findings similar to those seen in moyamoya disease, while T-cell dominant inflammatory changes were also shown at the terminal portion of the internal carotid artery (Panegyres et al., 1993).

Previous reports have shown associations between the disease and either 1) $A w 24, B w 46$, or $B w 54$ antigens in 18 patients (Kitahara et al., 1982) and 2) B51, 
$B 67, D R 1$ or $C w 1$ antigens in 32 patients (Aoyagi et al., 1995). In contrast to these reports, no such counterparts of these alleles were seen in this present study. This may be because of the small number of patients with a low specificity of serological typing reported in previous studies.

Interestingly, the affected alleles in the early-onset group were different from those in the late-onset groups. In this respect, it is important to note that the clinical features are different between the early- and the late-onset groups (Suzuki and Kodama, 1983). Thus, the initial symptoms are cerebral ischemia and cerebral hemorrhage in the early-onset and the late-onset groups, respectively. These observations suggest a different etiology for these two groups, in spite of their similar angiographical findings.

If associated alleles do not directly control the susceptibility to this disease, then some other responsible genes may be in linkage disequilibrium with these associated HLA alleles. Based on the above findings, moyamoya disease is considered to have some intrinsic factors in its etiology. To specify genetic backgrounds of moyamoya disease, further studies regarding linkage analysis are thus called for.

Acknowledgments Dr. Ikezaki, Dr. Fukui and Dr. Sasazuki were supported by research grants from the Ministry of Health and Welfare, Japan. We thank the following doctors who kindly helped in collecting the samples, Dr. Yoshiharu Sakurai (Sendai National Hospital), Prof. Hiromu Yamada (Gifu University), Prof. Kazuo Yamada (Nagoya City University), Prof. Toru Hayakawa (Osaka University), Prof. Satoshi Ueda (Kyoto Prefectural University of Medicine), Prof. Takashi Ohmoto (Okayama University). We also thank Ms. Chiharu Noguchi for her secretarial assistance.

\section{REFERENCES}

Achord JL, Gunn CH, Jackson JF (1982): Regional enteritis and HLA concordance in multiple sibrings. Dig Dis Sci 27: 330-332

Aoyagi M, Fukai N, Matsushima Y, Yamamoto M, Yamamoto K (1993): Kinetics of ${ }^{125 I-P D G F}$ binding and down-regulation of PDGF receptor in arterial smooth muscle cells derived from patients with moyamoya disease. J Cell Physiol 154: 281-288

Aoyagi M, Ogami K, Matsushima Y, Shikata M, Yamamoto M, Yamamoto K (1995): Human leukocyte antigen in patients with moyamoya disease. Stroke 26: 415-417

Bodmer JG, Marsh SGE, Albert ED, Bodmer WF, Bontrop RE, Charron D, Dupont B, Erlich HA, Mach B, Mayer WP, Darham P, Sasazuki T, Schneider GMT, Strominger JL, Svejguard A, Terasaki PI (1995): Nomenclature for factors of the HLA system. Tissue Antigens 46: 118

Burt RD, Vaughan TL, Nisperos B, Swanson M, Berwick M (1994): Protective association between the HLA-A2 antigen and nasopharyngeal carcinoma in US caucasians. Int $J$ Cancer 56: $465-467$

Date Y, Kimura A, Kato H, Sasazuki T (1996): DNA typing of the HLA-A gene: population study and identification of four new alleles in Japanese. Tissue Antigens 47: 93-101

Dong RP, Kimura A, Numano F, Nishimura Y, Sasazuki T (1992): HLA-linked susceptibility and resistance to Takayasu Arteritis. Heart Vessels Suppl 7: 73-80

Dong RP, Kimura A, Hashimoto H, Akizuki M, Nishimura Y, Sasazuki T (1993): Difference in HLA-linked genetic background between mixed connective tissue disease and systemic lupus erythematosus. Tissue Antigens 41: 20-25

Vol. 42, No. 4, 1997 
Fukui M, Kawano T (1996): Follow-up study of registered cases in 1995. In: Annual Report 1995 of the Research Committee on Spontaneous Occlusion of the Circle of Willis. pp 12-16 (in Japanese)

Gadoth N (1993): On the probrem of essential and secondary moyamoya and vascular dysplasia in Down syndrome. Brain Dev 15: 317-318

Goto Y, Yonekawa Y (1992): Worldwide distribution of moyamoya disease. Neurol Med Chir (Tokyo) 32: 883-886

Haldane $S$ (1956): The estimation and significance of the logarithm of a ratio of frequencies. Ann Hum Genet 20: 309-311

Hirayama K, Matsushita S, Kikuchi I, Iuchi M, Ohta N, Sasazuki T (1987): HLA-DQ is epistatic to HLA-DR in controlling the immune response to schistosomal antigen in humans. Nature 327: $426-430$

Hosoda Y (1984): Pathology of so-called spontaneous occlusion of the circle of willis. Pathol Annu 19: $221-244$

Hugot JP, Laurent-Puig P, Gower-Rousseau, Caillat-Zucman S, Beaugerie L, Dupas JL, Gossum AV, Bonaïti-Pellie C, Cortot A, Thomas G, the G.E.T.A.I.D. (1994): Linkage analyses of chromosome 6 loci, including HLA, in familial aggregations of Crohn disease. Am J Med Genet 52: 207-213

Ikeda E, Hosoda Y (1993): Distribution of the thrombotic lesions in the cerebral arteries in spontaneous occlusion of the circle of willis: cerebrovascular moyamoya disease. Clin Neuropathol 12: 44-48

Ikeda E, Maruyama I, Hosoda Y (1993): Expression of thrombomodulin in patients with spontaneous occlusion of the circle of willis. Stroke 24: $657-660$

Ikezaki K, Han HD, Kawano T (1997): Epidemiological survey of moyamoya disease in Korea. Clin Neurol Neurosurg 99 Suppl.2: S6-S10

Kanai N, Fukuyama Y (1992): A genetic study of spontaneous occlusion of the circle of willis (Moyamoya disease). Tokyo Joshi Ikadaigaku Zasshi 62: 1227-1258 (in Japanese with English abstract)

Kimura A, Sasazuki T (1992): Eleventh International Histocompatibility Workshop reference protocol for the HLA DNA-typing technique. In: Tsuji K, Aizawa M, Sasazuki T (eds). HLA 1991: Proceeding of the Eleventh International Workshop and Conference. Vol 1. Oxford University Press, Oxford, pp 397-419

Kimura A, Dong RP, Harada H, Sasazuki T (1992): DNA typing of HLA class II genes in B-lymphoblastoid cell lines homozygous for HLA. Tissue Antigens 40: 5-12

Kitahara T, Okumura K, Senba A, Yamaura A, Makino H (1982): Genetic and immunologic analysis on moyamoya. $J$ Neurol Neurosurg Psychiatry 45: 1048-1052

Kitamura K (1988): Revision of the diagnostic guide of the "Spontaneous occlusion of the circle of Willis." In: Annual Report 1987 of the Research Committee on Spontaneous Occlusion of the Circle of Willis. pp 119-122 (in Japanese)

Kudo T (1968): Spontaneous occlusion of the circle of Willis: a disease apparently confined to Japanese. Neurology 20: 485-496

Masuda J, Ogata J, Yutani C (1993): Smooth muscle cell proliferation and localization of macrophages and $T$ cells in the occlusive intracranial major arteries in moyamoya disease. Stroke 24: 1960-1967

Miettinen $O$ (1976): Estimability and estimation in case-referent studies. Am J Epidemiol 103: 226-235

Nishimoto A, Takeuchi S (1968): Abnormal cerebrovascular network related to the internal carotid arteries. J Neurosurg 29: 255-260

Nishimura Y, Sasazuki T (1987): Suppressor T cells control the HLA-linked low responsiveness to streptococcal antigen in human. Nature 327: 426-430

Panegyres PK, Morris JG, O'Neill PJ, Balleine R (1993): Moyamoya-like disease with inflammation. Eur Neurol 33: 260-263

Pavlakis SG, Verlander PC, Gould RJ, Strimling BC (1995): Fanconi anemia and moyamoya: 
evidence for an association. Neurology 45: 998-1000

Sasazuki T, Nishimura Y, Muto M, Onta N (1983): HLA-linked genes controlling the immune response and disease susceptibility. Immunol Rev 70: 51-75

Suzuki J, Takaku A (1969): Cerebrovascular moyamoya disease: disease showing abnormal net-like vessels in base of brain. Arch Neurol 20: 288-299

Suzuki J, Kodama N (1983): Moyamoya disease: a review. Stroke 14: 104-109

Suzuki H, Hoshimaru M, Takahashi JA, Kikuchi H, Fukumoto M, Ohta M, Itoh N, Hatanaka $M$ (1994): Immunohistochemical reaction for growth factor receptor in arteries of patients with moyamoya disease. Neurosurgery 35: 20-25

Todd JA, Acha-Orbea H, Bell JI, Acha-Orbea H, Bell JI, Chao N, Fronek Z, Jakob CO, Mcdermott M, Sinha AA, Timmerman L, Steinmann L, Mcdevitt HO (1988): A molecular basis for MHC class II-associated autoimmunity. Science 240: 1003-1009

Wakai K, Tamakoshi A, Ohno Y, Kawamura T, Ikezaki K, Fukui M (1996): Epidemiology of moyamoya disease in Japan: Findings from a nationwide survey. In: Annual Report 1995 of the Research Committee on Spontaneous Occlusion of the Circle of Willis. pp 33-38 (in Japanese)

Woody RC, Perrot LJ, Beck SA (1992): Neurofibromatosis cerebral vasculopathy in an infant: clinical, neuroradiologic, and neuropathologic studies. Pediatr Pathol 12: 613-619

Woolf B (1955): On estimating the relation between blood group and disease. Ann Hum Genet 19: $251-253$

Yamashita M, Oka K, Tanaka K (1991): Histopathology of the brain vascular network in moyamoya disease. Stroke 22: 1358-1362

Vol. 42, No. 4, 1997 